DOI: $10.30519 /$ ahtr.765420

Advances in Hospitality and Tourism Research (AHTR)

\title{
TRUSTWORTHINESS OF HOSTS IN ACCOMMODATION SHARING: THE EFFECT OF FACIAL TRAITS AND EXPRESSIONS
}

\author{
Aydin ERDEN 1 \\ Faculty of Communication, Bilgi University, Turkey \\ ORCID: 0000-0002-5124-8335 \\ Yonca ASLANBAY \\ Faculty of Communication, Bilgi University, Turkey \\ ORCID: 0000-0002-9084-9600 \\ Beril DURMUŞ \\ Faculty of Business Administration, Marmara University, Turkey \\ ORCID: 0000-0002-9679-9608 \\ Murat ÇİNKO \\ Faculty of Business Administration, Marmara University, Turkey \\ ORCID: 0000-0001-8560-7482
}

\begin{abstract}
The purpose of this paper is to reveal the impact of a host's facial traits and expressions on their perceived trustworthiness and preferences among users of accommodation-sharing platforms. The eye movements of 39 participants in the study while responding to the question of how much they would want to stay in each apartment presented on a created platform were recorded using an eye-tracking device in a controlled offline setting. A further online questionnaire was used to collect data about user preferences, to which 226 people responded. The results reveal the human face to be the most significant source of cognizance on accommodation sharing platforms; that hosts with positive profile photos are trusted and preferred more than those with less positive images; and that hosts with high fWHRs are trusted and preferred less than hosts with lower fWHRs. This
\end{abstract}

Article History

Received 7 July 2020

Revised 21 January 2021

Accepted 29 January 2021

Available online 9 Feb. 2021

\section{Keywords}

perception

trustworthiness

accommodation sharing facial width height ratio emotional expressions hospitality

\footnotetext{
${ }^{1}$ Address correspondence to Aydın Erden, Faculty of Communication, Bilgi University, Istanbul, Turkey. E-mail: aydin@aydinerden.com
} 


\section{INTRODUCTION}

The growth of sharing economy applications facilitating the exchange of goods and services between individuals has changed the business landscape (Botsman \& Rogers, 2010). These so-called peer-to-peer (P2P) systems remove the need for traditional intermediaries between the buyers and sellers of products or services and have become intermediaries themselves. A P2P platform makes it possible for buyers to connect with sellers directly, creating a whole new sharing experience, even between strangers. Accommodation sharing is one of the leading lights in the P2P sharing economy, having gained considerable popularity in recent years (Lauterbach et al., 2009). As is the case with all business transactions, trust is a major pre-condition in accommodation sharing, in which human interaction is a core feature. Sharing among people who do not know each other comes with certain safety concerns for those involved, and is stated to be one of the major reasons why some people avoid such applications (Nowak et al., 2015). Within such new sharing patterns, in which the accommodation sharing options range from an entire home to private rooms, and even shared rooms, building trust between the guests and hosts remains as a considerable challenge (Kim et al., 2011; Ponte et al., 2015).

There have been various studies to date investigating the effects of the information shared on accommodation sharing platforms on trustbuilding and apartment preferences, including the gender of the host $\mathrm{Wu}$ et al., 2017); non-demographic host quality attributes (Xie \& Mao, 2017); the reputation of the host (Zhang et al., 2018); and the hosts' self-definition (i.e. well-traveled) (Tussyadiah \& Park, 2018). In particular, the impact of profile photos has been studied, and the effect of the host's attractiveness on apartment rental prices (Jaeger et al., 2018). Furthermore, there have been other studies addressing the effect of profile photos on perceived trustworthiness (Barnes \& Kirshner, 2021; Ert et al., 2016; Jaeger et al., 2018), indicating that the profile photo variable affects perceived trustworthiness, user behavior and prices on these platforms.

To the best of our knowledge, however, there have been no studies to date in the field of tourism and hospitality investigating the individual variables related to such photos and their influence on perceptions of trustworthiness. The present study adopts a multidisciplinary approach to investigate how perceptions in this regard affect consumer choices, drawing upon studies in the field of cognitive sciences with focus on the human face and its influence on human perception (Todorov, 2008; Todorov et al., 2009; Valentine et al., 2014). These two fields are brought together in an approach 
that focalizes the facial variables in profile photos, and clarifies their effects on guest choice. More specifically, the impact of emotional expressions and facial traits reflected in profile photos on the perceived trustworthiness of the host, and the effect of this perception on the accommodation choices of guests are investigated.

This approach is further augmented with an investigation of the effect of the facial-width-height ratio (fWHR) - a recently studied variable related to the human face (Weston et al., 2007). It was found that this variable also affects perceptions of trustworthiness through the mediation of aggressiveness perception, and so can be deemed appropriate for inclusion in the present study (Carré \& McCormick, 2008; Carré et al., 2009, 2010; Haselhuhn et al., 2015; Hehman et al., 2013; Lefevre \& Lewis, 2014; Neth \& Martinez, 2009).

Accommodation-sharing platforms aid guest choice by providing several different variables, which can be listed as apartment photo, profile photo of the host, rating score and apartment description (Guttentag, 2015). Although there have been various studies analyzing the effects of these variables (Ert et al., 2016; Zhang et al., 2018), to the best of our knowledge there has been no research to date identifying which of these variables carries more weight among the users of such platforms. Studies have revealed the human face to be one of the most significant sources of information (Mondloch et al., 1999), and there are many cognitive resources in the human brain involved in the analysis and study of the human face aimed at extracting as much data as possible (Hassin \& Trope, 2000), although face to trait inferences are known to be intuitive (Engell et al., 2007; Todorov et al., 2009). All of these findings suggest that although guests may be presented with many variables, they will tend to focus more on the profile photos. To test this assumption, an eye tracker device is used to identify the points of focus of users on the accommodation selection screen of the application, and the results were recorded for analysis.

The data were collected in three separate stages, the first of which was a preparation stage for the main study during which images of apartments with a similar level of appeal were selected for use in the simulated platform. In the second stage, eye-tracking data was collected from the 39 participants of the study while making selections of apartments to stay. The results revealed the most important and attention-grabbing variable on the accommodation selection screens to be the profile photos of the hosts. In the third stage of the study, online data were collected in the form of responses from a total of 226 participants, revealing that hosts with 
profile photos with positive expressions are trusted and preferred more than other expressions, and that hosts with high fWHRs were perceived as less trustworthy, and so were preferred less than those with lower fWHRs.

In the following section we make a brief review of literature related to the sharing economy, after which we present our conceptual framework and discuss the concepts of visual perception, the importance of the human face and its effect on trust-building and trustworthiness perception, the variables that affect this perception in the human face, and the importance of the human face as a source of visual information. In the final sections, we present our study and the main results, and discuss their practical and theoretical implications.

\section{SHARING ECONOMY}

Technological developments have led to the creation of new modes of communication, and subsequently, to the establishment of platforms for various sharing practices. Recent literature has addressed the topics of product exchange (Ozanne \& Ballantine, 2010), car sharing (Bardhi \& Eckhardt, 2012), free and commercial re-distribution (Albinsson \& Perera, 2009; Denegri-Knott \& Molesworth, 2009), crowdfunding (Belleflamme et al., 2014; Cheung \& Chan, 2000), expertise and skill sharing (Bagozzi \& Dholakia, 2006; Postigo, 2003), information sharing (Reagle, 2010; Voss, 2005), content sharing and (Hennig-Thurau et al., 2007; Sinclair \& Green, 2015) accommodation sharing (Lauterbach et al., 2009; Zervas et al., 2017).

Peer-to-peer (P2P) sharing practices are becoming increasingly common, especially those with focus of accommodation and travel, with Airbnb and Couchsurfing emerging as the two main accommodationsharing platforms. As of 2019, Airbnb was operating in 220 countries and in 100,000 cities around the globe, and hosts making use of the Airbnb platform for the advertising of their properties have earned more than 80 billion USD to date (2020 Airbnb Update, 2020). Figures show that Airbnb enjoys significant market share in the tourism sector. Although the company makes considerable investments (150 million USD in 2019) into user protection tools, in other words, into building trust among its users, with privacy and safety concerns being still rife among the platform's users (Nowak et al., 2015). Accordingly, there may be considerable benefit in determining how trust is formed among the users of accommodationsharing platforms. 


\section{CONCEPTUAL FRAMEWORK}

In daily life, the trust one chooses to place in another person begins at first contact, and is updated with each subsequent contact (Wilson \& Eckel, 2006). People tend not to collaborate with new people until the trust between them reaches a certain level, necessitating a certain amount of repeat contacts until the required level of trust has been attained. The transactions entered into accommodation sharing are realized between strangers, and in most cases are not repeated between the same two people. Accordingly, opportunities to create and maintain trust through experience are lacking, increasing the importance of perceived trustworthiness at the point of first contact between the host and the guest.

Previous studies have examined the effects of the safety checks made by accommodation sharing platforms, and found that such host attributes as the time of reservation confirmation, the acceptance rate of renter reservations, the number of listings owned, whether a personal profile page is disclosed, and the gender of the host significantly affect renter reservations (Wu et al., 2017). Non-demographic host quality attributes (i.e., having longer operating experience and a higher response rate), on the other hand, have a positive effects on future reservations of host listings (Xie \& Mao, 2017). For instance, reputation plays a key role in the establishment of trust on accommodation-sharing platforms (Zhang et al., 2018), where hosts who portray themselves as well-traveled and eager to meet new people are considered more trustworthy and desirable that those who disclose their profession as their personal identity (Tussyadiah \& Park, 2018).

Both Airbnb and Couchsurfing request profile photos, along with verified IDs, from all users showing personal information (Guttentag, 2015; Liu, 2012), and exhibit rating scores and comments on the profile pages (Resnick \& Zeckhauser, 2002). Literature shows that in a strategic trustbased economy, stakeholders value information they can draw from faces (Ewing et al., 2015). For example, in business decisions, decision-makers strongly prefer face-to-face meetings, even for the execution of legal contracts (Eckel \& Petrie, 2011). Eckel and Petrie (2011) found that the human face provides substantial data in this type of decision-making process. More specifically, faces carry trustworthiness cues (Engell et al., 2007; Todorov et al., 2009). Perceptions of trustworthiness based on the face have proven effects on decisions and behaviors. A positive correlation was identified between the trustworthiness perception drawn from a face and tendency to cooperate, (Van 't Wout \& Sanfey, 2008), and to avoid 
cooperation in the event of a perception of untrustworthiness drawn from a face (Chang et al., 2010; Rezlescu et al., 2012; Stirrat \& Perrett, 2010; Tingley, 2014).

There have also been numerous studies examining directly the relationship between profile photos and perceived trustworthiness on accommodation-sharing platforms. Specifically, studies of accommodation sharing have found that "trustworthy photos" contribute to the establishment of trust (Bente et al., 2012), and influence the selection of accommodation (Ert et al., 2016). Ert et al. (2016) found that the more trustworthy the host was perceived to be from his/her photo, the higher the price of the listing and the likelihood of selection. Jaeger et al. (2019) expanded upon the findings of Ert et al. (2016) by controlling for additional features related to price and the influence of other host features, such as race and facial expression (Jaeger et al., 2019), identifying effects related to racial differences on prices and a positive correlation between the smile intensity of the host and the rental price. Barnes and Kishner (2021) classified profile photos using a deep learning application and found that trust along with attractiveness led to 5 percent higher Airbnb listing prices. Although the level of trustworthiness perceived from profile photos was taken into account in all three of the above studies, no investigation was made of the facial variables linked to perceived trust. The main aim of the present study is to fill a gap in literature by combining the findings of cognitive science studies focused on human face variables with those of studies investigating tourism and hospitality.

\section{The human face: a source of information determining accommodation preferences}

Visual processing is one of the leading ways in which survival data is obtained from one's environment (Zebrowitz et al., 1996), which is why humans constantly look around and use their visual inputs to guide their behaviors. One of the major sources of visual information is the human face, which can convey a vast amount of information that is highly relevant to social life, and that is crucial to detect for the production of adaptive responses within different contexts (Zebrowitz et al., 1996). Infants spend more time looking at faces rather than non-facial stimuli (Cassia et al., 2004; Valenza et al., 1996). Faces grab attention, even if presented peripherally and completely irrelevant to the task (Devue \& Grimshaw, 2017). A face still pops out when it is presented among non-facial distractor objects (Hershler \& Hochstein, 2005; Langton et al., 2008), and it can thus be stated that faces have a unique capacity to attract attention. 
The parts of the human brain that interpret and store information on human faces are remarkable (Bahrick et al., 1975), acting in accordance with the desire to extract as much information as possible from the faces of others (Hassin \& Trope, 2000), and this desire is instinctual (Mondloch et al., 1999). Even a brief glance at a face allows many inferences to be made, such as physical health, identity, age (Grammer \& Thornhill, 1994), attractiveness (Rhodes, 2006), emotions (Ekman, 1993) and personality (Willis \& Todorov, 2006). Although humans may seem to make many different and separate inferences, is claimed in the cognitive sciences that people evaluate others from their faces based on two main dimensions: valence and dominance (Todorov et al., 2008). Each of the adjectives that they use to identify others corresponds to a point in this two-dimensional evaluation range. Valence is the dimension through which humans evaluate the intentions of others, while dominance is the dimension through which humans evaluate the capacity of others to follow through with those intentions. Valence dimension evaluations have been found to take priority over those of the dominance dimension, while the trustworthiness evaluation of others takes priority over all other evaluations, and is one of the major sub-dimensions of the valence dimension (Todorov et al., 2008). On the Airbnb main listing screen, four main variables are presented to browsers, being a photo of the host, photos of the apartment, the host's rating score and an apartment description, and visitors to the application base their evaluations on all four of these variables. In parallel with the findings of a brief literature review, the present study assumes that guests will base their trustworthiness evaluations primarily on the photo of host in the profile.

Studies have suggested that a relationship exists between mental processing depth and visual focus, namely fixation position and fixation duration (Henderson et al., 2013). Close or direct fixation on an object or scene region is necessary for the perception of local visual details, for the unambiguous identification of objects, and for the encoding of the object and the scene information into the short- and long-term memory. As such, monitoring eye fixation positions and durations of fixation, namely visual focus, to determine which variable on the screen grabs primary attention (which is subjected to a deeper mental process) can be considered the most appropriate approach to the evaluation of the stated assumption. Accordingly, the following hypothesis is proposed:

H1: Due to the instinctual desire of guests to evaluate the trustworthiness of hosts, the total gaze duration of users on the profile photo of the apartment owner (host) on the screen will be more than that accorded to the apartment photo, the rating of the host and the apartment description text. 
Facial expressions and traits: impact of expressed emotions and facial width-height ratio on the perceived trustworthiness of hosts

Secord (1958) suggests that people may perceive temporary emotions reflected in the faces of strangers as a permanent personality trait, which Todorov (2008) expanded upon later with the emotion face overgeneralization hypothesis (Secord, 1958). Krumhuber et al. (2007) found that the level of trust placed in a person and their willingness to cooperate are affected by subtle dynamics that are reflected in the face of an individual, as a result of this tendency. Accordingly, happy expressions were found to be perceived as more trustworthy, while angry expression faces were linked to untrustworthiness. In addition to their effect on the perceived trustworthiness, people with happy facial expressions are perceived to be more cooperative (Montepare \& Dobish, 2003). Hence, consistent with previous studies:

$\mathrm{H} 2$ : On accommodation sharing platforms, guests perceive hosts with happy expression profile photos as more trustworthy than those with neutral expression profile photos, and so the apartments of hosts with happy expression profile photos tend to get more custom.

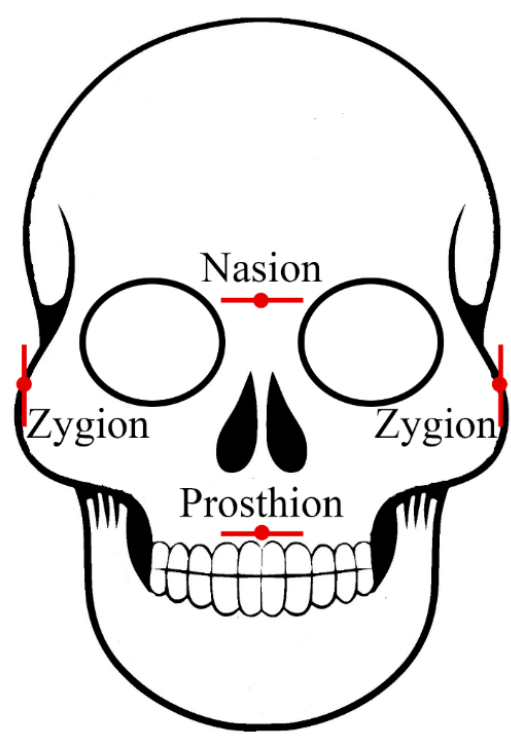

Figure 1. Cranial landmarks of Nasion, Zygion and Prosthion

Recently, the human facial width-height ratio (fWHR) has been identified in literature as a variable affecting perceptions of personality (Weston et al., 2007). It has been claimed that the testosterone levels of males during adolescence affect fWHR (Lefevre et al., 2013), with higher 
testosterone levels being related to higher fWHRs, meaning broader and shorter faces. fWHR is calculated by dividing the distance between the left and right Zygion points by the distance between the Prosthion (the very top of the upper lip) and Nasion (center of the eye brows), being the four cranial landmarks shown in Figure 1 (Weston et al., 2007).

A significant correlation has been identified between fWHR and perceived aggressiveness (Carré et al., 2010) in both males and females (Lefevre \& Lewis, 2014). Neth and Martinez (2009) reported that a person appears to be more aggressive when the fWHR is increased through the manipulation of the distance between the eyes and mouth on an image, and such a manipulation also affects the perceived trustworthiness of the person in the photo (Stirrat \& Perrett, 2010). A negative correlation has also been identified between aggressive appearance and perceived trustworthiness. Geniole et al. (2014) found aggressiveness to be a mediating variable between fWHR and perceived trustworthiness, and a positive correlation has been noted between perceived aggressiveness and fWHR in a number of different studies (Haselhuhn et al., 2015; Lefevre \& Lewis, 2014). As mentioned previously, trustworthiness evaluations are one of the main subdimensions of the valence dimension, relating mainly to the evaluation of the intentions of others. Since an aggressive appearance conveys visual information about the unfavorable intentions of a person, the correlation between an aggressive appearance and perceived trustworthiness is negative (Carré et al., 2009). The more aggressive a person looks, the more untrustworthy they are perceived. This raises the question of whether a relatively higher fWHR in the host corresponds to a decrease in their perceived trustworthiness, regardless of their actual aggressiveness, and this may lead to them being less preferred. Accordingly, the following two hypotheses are proposed.

H3: Guests perceive hosts with happy expression profile photos to be more trustworthy than those with neutral expression fWHR-increased profile photos, and as a consequence, the accommodation offered by hosts with happy expression profile photos tend to be preferred more.

H4: Guests perceive hosts with neutral expression profile photos to be more trustworthy than those with neutral expression fWHR-increased profile photos, and consequently, hosts with neutral expression profile photos tend to be preferred more.

Figure 2 presents a graphic of the research model. 


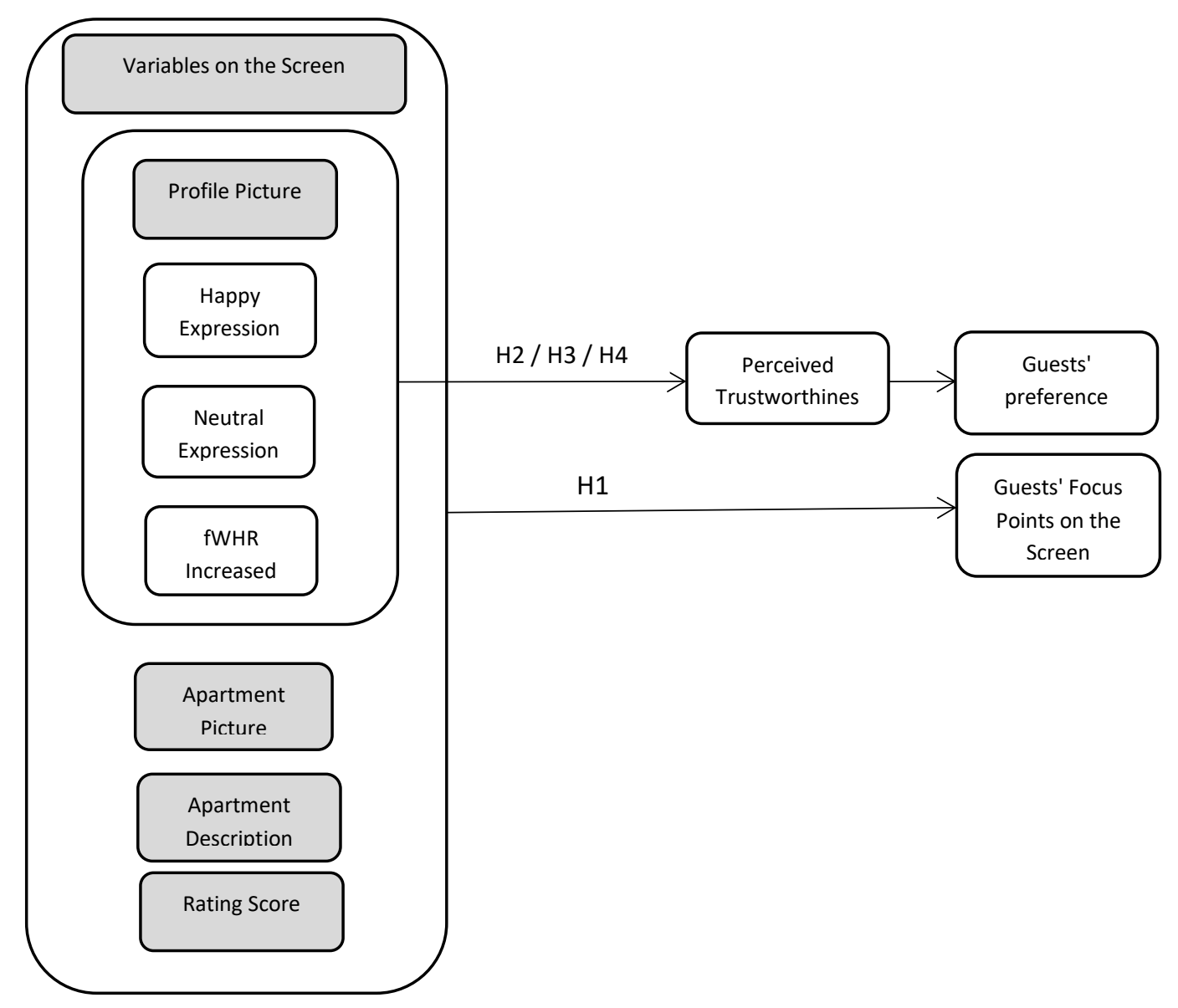

Figure 2. Research Model

\section{METHODOLOGY}

The hypotheses were tested by three studies (see Table 2), all of which involved data from Turkey. There are two rationales that make Turkey an ideal setting for the study. The first of these is that Turkey has a high average spending on the Sharing Economy when compared to many other countries (Table 1). The average per-user contribution to the sharing economy was $€ 1,031$ in 2016 (Beutin, 2017).

Table 1. Average per-user contribution to the Sharing Economy in one year (Beutin, 2017)

\begin{tabular}{lc}
\hline Country & Average Spent \\
\hline Turkey & $1.031 €$ \\
Switzerland & $939 €$ \\
Germany & $884 €$ \\
Belgium & $615 €$ \\
Austria & $574 €$ \\
The Netherlands & $506 €$ \\
\hline
\end{tabular}


Secondly, trust is a major issue in Turkey, where uncertainty avoidance, defined by Hofstede as "... the extent to which the members of a culture feel threatened by ambiguous or unknown situations" is rated rather high at 85 out of 100 (Hofstede, 2018). Some 12 percent of Turkish people agree with the statement "most people can be trusted", (Ortiz-Ospina \& Roser, 2018) and Turkish people scored an average of 2 on a 5-point Likert-type scale measuring "trust at first contact", in which 5 indicated the highest level of trust (Konda, 2012). A simulated digital accommodation-sharing platform (www.gezgineyuva.com) resembling commercial accommodation -sharing platforms was created for the study, and was used in all three stages of the study, although different data collection methods were utilized in each stage.

Table 2. Summary of studies

\begin{tabular}{ccccc}
\hline $\begin{array}{c}\text { Study } \\
\text { Number }\end{array}$ & Purpose & $\begin{array}{c}\text { Tested } \\
\text { Hypothesis }\end{array}$ & $\begin{array}{c}\text { Data Collection } \\
\text { Method }\end{array}$ & $\begin{array}{c}\text { Data Collection } \\
\text { Platform }\end{array}$ \\
\hline Study 1 & $\begin{array}{c}\text { Selection of the Apartment } \\
\text { Photos for Study 1 and 2 }\end{array}$ & N/A & $\begin{array}{c}\text { Online } \\
\text { Survey }\end{array}$ & Online Survey \\
\hline Study 2 & $\begin{array}{c}\text { Research of users' points } \\
\text { of interests on } \\
\text { accommodation selection } \\
\text { screens }\end{array}$ & H1 & $\begin{array}{c}\text { Offline } \\
\text { Eye Tracking } \\
\text { Device }\end{array}$ & $\begin{array}{c}\text { A simulated } \\
\text { accommodation } \\
\text { sharing platform }\end{array}$ \\
\hline Study 3 & Research of user decisions & H2, H3, H4 & $\begin{array}{c}\text { Online } \\
\text { Apartment } \\
\text { Preferences } \\
\text { Recorded }\end{array}$ & $\begin{array}{c}\text { www.gezgineyuva.com } \\
\text { A simulated } \\
\text { accommodation } \\
\text { sharing platform }\end{array}$ \\
\hline
\end{tabular}

\section{Study 1 - Selection of Apartment Photos}

Given that the aim of the research was to measure the effect of profile photos on user decisions, the effect of other variables, including apartment photos, should be neutralized. It was considered that especially the appeal of the apartment photos would have a considerable effect on participant choices, which made the selection of apartment photos to be used in the research a critical issue. Rather than using a single standard photo to neutralize the effect of the apartment photo, photos with a similar level of appeal were used in the research to make the platform more authentic. To this end, an initial research was carried out to identify apartment photos with a similar level of appeal.

\section{Data collection}

Data were collected from online sources, and the study sample included 228 people who were contacted through a convenience sampling method, and 
who participated in the research voluntarily. The mean age of the participants was 39.6 years (SD 10.56), 65 percent were female and 35 percent were male, and all were familiar with accommodation-sharing portals.

\section{Measures}

A total of 25 apartment photos were procured from www.shutterstock.com, and an online survey was conducted in which the participants were asked to rate how much they liked each apartment on a 7-point Likert scale, ranging from "did not like at all" (1 point) to "liked very much" (7 points).

\section{Analysis and results}

The data recorded for each photo was subjected to a paired samples t-test with all other photos, and six apartment photos were identified as having a similar level of appeal (see Table 3) that were used subsequently in studies 2 and 3.

Table 3. Apartment Photos Paired Samples t-test Results

\begin{tabular}{ccccc}
\hline Code & Mean & Code & Mean & \\
\hline Apartment 1 & $4.28(1.673)$ & Apartment 6 & $4.30(1.501)$ & $\mathrm{t}=0.189$ \\
Apartment 1 & $4.28(1.673)$ & Apartment 5 & $4.22(1.667)$ & $\mathrm{t}=-0.586$ \\
Apartment 1 & $4.28(1.673)$ & Apartment 4 & $4.24(1.474)$ & $\mathrm{t}=-0.352$ \\
Apartment 1 & $4.28(1.673)$ & Apartment 3 & $4.21(1.652)$ & $\mathrm{t}=-0.595$ \\
Apartment 1 & $4.28(1.673)$ & Apartment 2 & $4.25(1.517)$ & $\mathrm{t}=-0.305$ \\
Apartment 2 & $4.25(1.517)$ & Apartment 6 & $4.30(1.501)$ & $\mathrm{t}=0.535$ \\
Apartment 2 & $4.25(1.517)$ & Apartment 5 & $4.22(1.667)$ & $\mathrm{t}=-0.240$ \\
Apartment 2 & $4.25(1.517)$ & Apartment 4 & $4.24(1.474)$ & $\mathrm{t}=-0.085$ \\
Apartment 2 & $4.25(1.517)$ & Apartment 3 & $4.21(1.652)$ & $\mathrm{t}=-0.396$ \\
Apartment 3 & $4.21(1.652)$ & Apartment 6 & $4.30(1.501)$ & $\mathrm{t}=0.885$ \\
Apartment 3 & $4.21(1.652)$ & Apartment 5 & $4.22(1.667)$ & $\mathrm{t}=0.114$ \\
Apartment 3 & $4.21(1.652)$ & Apartment 4 & $4.24(1.474)$ & $\mathrm{t}=0.301$ \\
Apartment 4 & $4.24(1.474)$ & Apartment 6 & $4.30(1.501)$ & $\mathrm{t}=0.619$ \\
Apartment 4 & $4.24(1.474)$ & Apartment 5 & $4.22(1.667)$ & $\mathrm{t}=-0.152$ \\
Apartment 5 & $4.22(1.667)$ & Apartment 6 & $4.30(1.501)$ & $\mathrm{t}=0.739$ \\
\hline
\end{tabular}

\section{Study 2 - Research of Users' Points of Interest On Accommodation Selection Screens}

A simulated digital accommodation sharing platform was created for the testing of $\mathrm{H} 1$. The placement of profile photos, apartment photos, apartment description texts and rating scores on the screen were laid out to 
resemble as much as possible existing accommodation sharing platforms (see Figure 3). The eye movements of the participants were recorded in a controlled environment while responding to the question of how much they would want to stay at each apartment based on the data presented on the platform.

\section{Data collection}

The participant group comprised convenient undergraduate university students and scholars, all of whom were informed about the research and participated voluntarily. The data were collected in an offline setting under the supervision of the researchers. The responses of the participants took an average of 19 minutes. A total of 39 participants $(69.2 \%$ male and $30.8 \%$ female; $90 \%$ aged $23-41$ and $10 \%$ aged $42-53 ; 97.4 \%$ with at least a bachelor's degree) responded to the survey. All participants were familiar with accommodation-sharing applications.
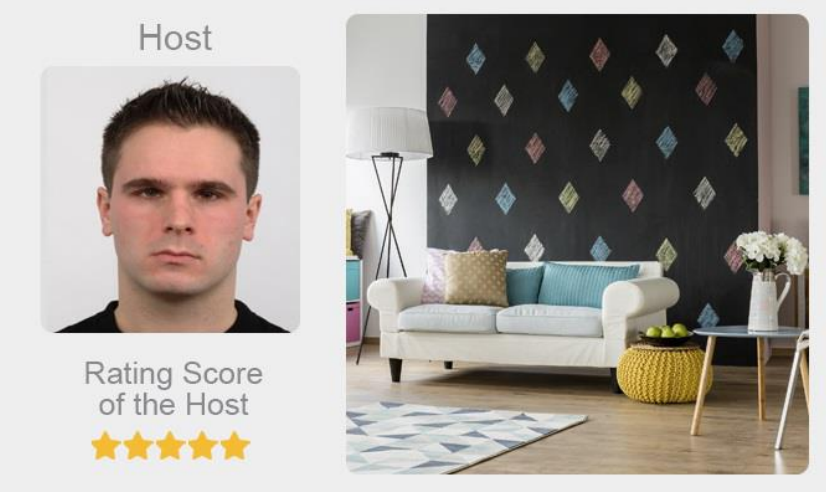

A washing machine, dryer, ironing board and iron are available. Guests can also use the

kitchen as they wish. Central heating and air conditioning are available. Wifi internet is

available. It has a comfortable setting with new furniture. There is a bathroom and a hairdryer.

LCD TV and music system are available. The venue is located near to the city centre.

Would you like to share habitation of this apartment with the owner

for one night?

1 - Definitely No $\leftrightarrow 10$ - Definitely Yes

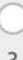

56

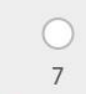

8

$9 \quad 10$

Next $\rightarrow$

Figure 3. An example screen

\section{Stimuli}

A total of nine apartment alternatives, using a combination of nine profile photos and six apartment photos, served as stimuli for the study. As is the case with real accommodation-sharing platforms, the postings included 
profile photos, apartment photos, host rating scores and written information about the apartment, as the four main variables shown to the users (see Figure 3 for an example screen).

The main variable used in the research was the profile photo, for which nine male profiles from the Radboud Faces Database were selected from among 38 different male profiles using randomization software (Langner et al., 2010). The database contains photographs of people who have undergone training in the Facial Action Coding System (FACS), and gave form to their faces accordingly (Ekman et al., 2002). Only happy and neutral facial expressions, viewed from the front and looking directly into the camera, were used for the research. A tilted head invokes perceptions of dominance, and so the person is perceived to be more dominant when the head is upright (Mignault \& Chaudhuri, 2003). Since in the Radboud Faces Database all heads are upright, the effect was the same in all photos.

In addition to the happy and neutral expressions of the nine males selected from the database, a further facial type was created by increasing the fWHR of the neutral photos. fWHR values of all profile photos have been increased between $12 \%$ and $13 \%$. The neutral photos were selected for manipulation due to the potential of facial expressions to manipulate the facial width height ratio (Kramer, 2016). After the fWHR of each profile was increased, happy, neutral and fWHR-increased profile photos of the nine male profiles were made ready for use in the research. A sample male profile featuring all three photo types is presented in Figure 4.

Each participant was presented with three randomly selected happy expression (unmanipulated), neutral expression (unmanipulated) and neutral expression (fWHR increased) profile photos (nine photos in total) on apartment selection screen.
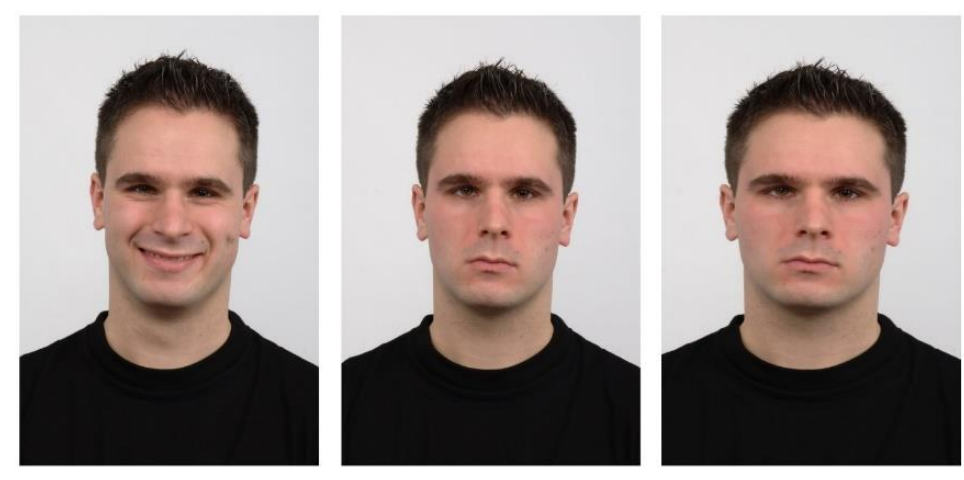

Figure 4. Sample male profile - from left to right: happy expression (unmanipulated), neutral expression (unmanipulated) and neutral expression (fWHR increased). 
Each participant rated how much wanted to share habitation of the apartment with the owner for one night in each of the nine presented apartment alternatives on a 10-point Likert scale, with the two polarized ends of the scale being "definitely no" (1 point) and "definitely yes" (10 points). The screens used in the research were generated using software incorporating an algorithm that presented nine unique screens to each user. As mentioned previously, each screen contains four basic variables. The software carries out the following operation for each user, providing nine unique apartment alternatives to each participant. The program begins by creating nine random male profiles, and then randomly selects one of the three image types (happy, neutral, fWHR increased) for each male profile. While making these random selections, it ensures that three happy, three neutral and three fWHR increased are selected and presented to each respondent, in random order and with random profile values. Since six apartment photos were identified with a similar level of appeal, these six photos were sorted randomly and used for the first six apartment alternatives. For the seventh, eighth and ninth apartment alternatives, the apartment photos used for the first, second and third apartment alternatives were used in the same order again, bringing the number of apartment photos to nine. These randomizations prevented any potential effects of the order of photos and any deviations that may arise from the use of the same profiles with the same type of apartment photo. In all accommodation alternatives, in apartment description texts the order of the sentences was changed randomly to ensure that participants do not realize they are reading the same text. Finally, the rating scores of hosts were fixed at 5 stars in all alternatives. Any potential effect of the apartment description texts and the rating scores of the hosts were thus neutralized through the use of the same texts and the same rating scores for all apartment alternatives.

\section{Apparatus}

The participants viewed the screens on a flat-screen monitor with a resolution of 1920x1080 pixels and a refresh rate of $100 \mathrm{~Hz}$, controlled by a PC running the Windows 10 OS and iMotions software (iMotions, 2017). Eye movements were recorded using an EyeTribe desk-mounted eye tracker with a $20 \mathrm{~ms}$ response rate, also controlled by iMotions software. The participants sat approximately $60 \mathrm{~cm}$ from the screen, and a standard optical mouse was used to record the survey responses. 


\section{Procedure}

Before taking part in the survey, the respondents were informed about the purpose of the study and provided written consent for their participation. The eye-tracking involved a standard nine-point calibration procedure. For the system calibration, the eye-tracking software calculates the user's eye gaze coordinates with an average accuracy of around $0.5^{\circ}$ to $1^{\circ}$ of visual angle. When the user is located approximately $60 \mathrm{~cm}$ away from the screen/tracker, this accuracy corresponds to an on-screen average error of 0.5 to $1 \mathrm{~cm}$. Upon the successful completion of the calibration process, the respondents rated their desire to stay in each alternative apartment on a 10point Likert scale. No time limit was applied during the survey, and the respondents' eye movements were recorded.

\section{Analysis and results}

The eye movement data (horizontal and vertical coordinates on the screen) were automatically parsed into saccades and fixations by the iMotions software. An example eye tracking heat map presented in Figure 5.

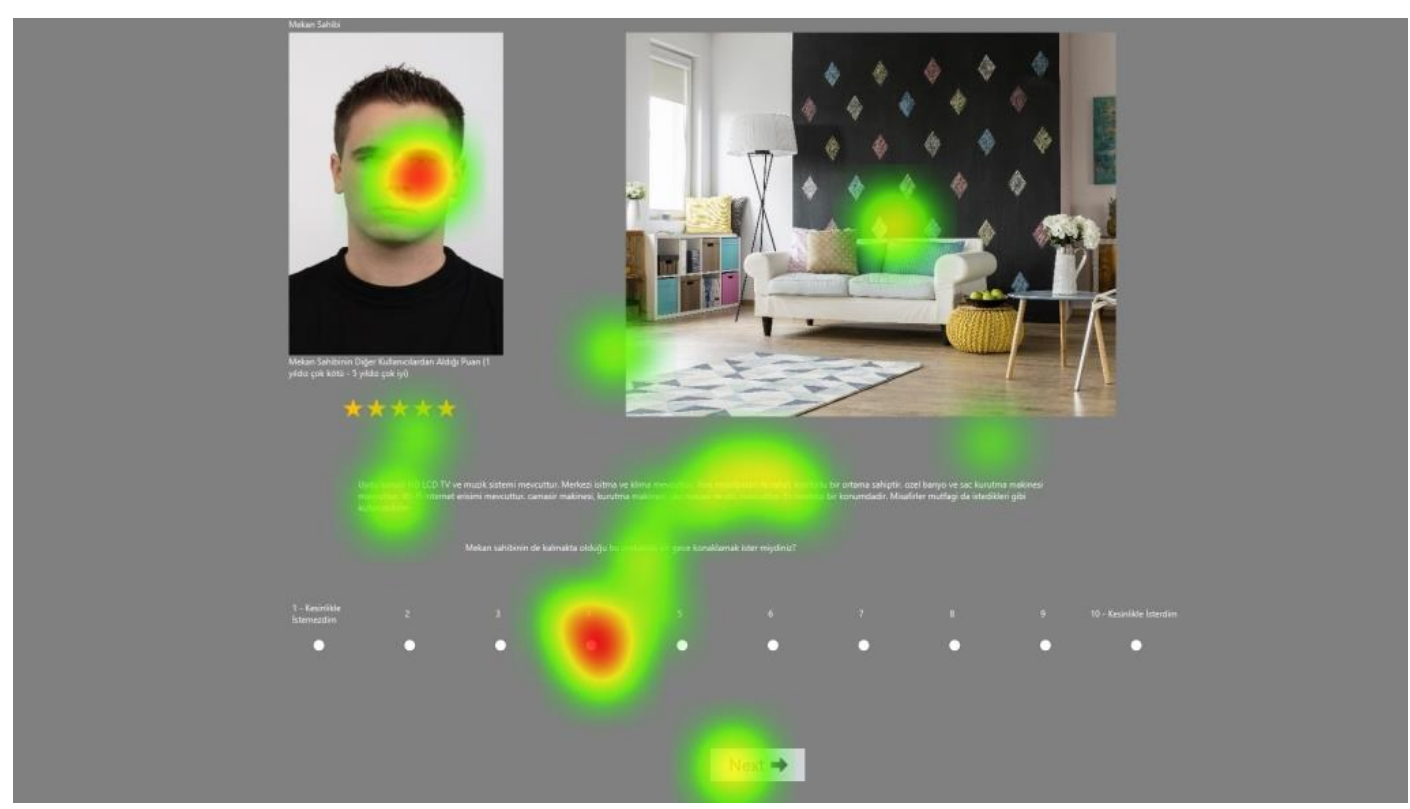

Figure 5. An eye tracking heat map for a screen

Earlier studies have suggested a link between depth of processing and fixation duration (Henderson et al., 2013; Nuthmann et al., 2010), and so only the fixation durations were analyzed as meaningful data, as it can be assumed that information extraction takes place only at these points. The iMotions software decomposed the fixation durations according to the areas of interest (AOI). The profile photos, apartment photos, apartment 
descriptions and rating scores of the hosts were identified as AOIs. Durations were all in milliseconds, and the dwell times for each AOI were computed as the sum of the fixation durations on that AOI.

A non-parametric Kruskal-Wallis test was used to compare the mean durations of the four AOIs, revealing that the profile photo was the AOI with the highest mean rank score, and that there was a statistically significant difference in the fixation durations on the AOIs, $\chi 2(3)=155.472$, $p=0.000$ (see Figure 6 for the mean rank scores).

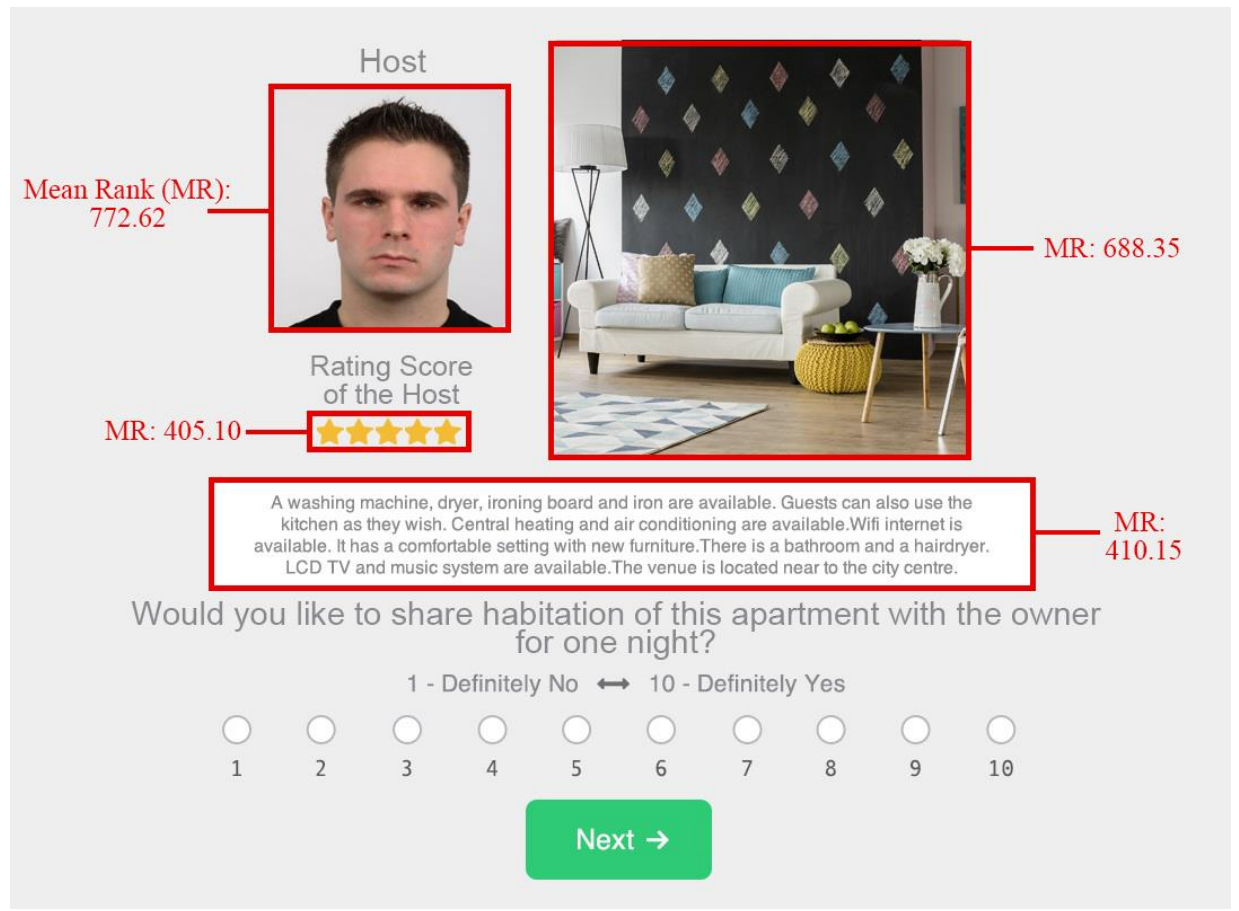

Figure 6. Mean rank scores of AOIs

Mann-Whitney $U$ tests were conducted for pairwise comparisons (Table 4). The analysis revealed that the fixation durations on different AOIs differed significantly from each other, aside from those on the apartment descriptions and rating scores, indicating that the variable attracting the most attention on the apartment selection screen was the profile photo of the host. H1 was thus accepted.

Table 4. Pairwise comparisons of AOIs

\begin{tabular}{lcc}
\hline AOI Pair & Mann Whitney U & p-value \\
\hline Apartment Description - Apartment Photo & 17490.000 & 0.000 \\
Apartment Description - Profile Photo & 18022.500 & 0.000 \\
Apartment Description - Rating Score & 7309.500 & 0.573 \\
Apartment Photo - Profile Photo & 131102.000 & 0.000 \\
Apartment Photo - Rating Score & 17458.500 & 0.000 \\
Profile Photo - Rating Score & 17081.000 & 0.000 \\
\hline
\end{tabular}




\section{Study 3 - Research of User Decisions}

Study 3 was conducted to test hypotheses $2-4$, for which an online survey was conducted using an expanded version of the simulated accommodation platform developed in study 2 with the addition of a profile photo trustworthiness evaluation survey module. The platform was designed to be equally viewable on different devices and different screen sizes.

\section{Data collection}

Online survey data was garnered from 226 participants (38.9\% male; $61.1 \%$ female) who were accessed through a convenience sampling method, and who participated in the study voluntarily (Table 5).

Table 5. Profile of the participants

\begin{tabular}{lcc|lll}
\hline Age Group \& Generation & $\mathbf{n}$ & $\mathbf{\%}$ & Education Level & $\mathbf{n}$ & $\mathbf{\%}$ \\
\hline 19-22 / Z generation & 70 & 31 & High School & 6 & 3 \\
23-41 /Y generation & 109 & 48 & Associate \& Bachelor's Degree & 130 & 57 \\
42-53 / X generation & 41 & 18 & Master's Degree & 63 & 28 \\
54-66 / Baby boomers & 6 & 3 & Doctorate & 27 & 12 \\
\hline
\end{tabular}

According to the PricewaterhouseCoopers Share Economy report (Beutin, 2017), the majority of users of the sharing economy, especially in the accommodation field, are well educated, with 70 percent having obtained a high school diploma or higher. The same report stated that the average age of Turkish users of the sharing economy was 37.8 years (Beutin, 2017), which concurs with the age and education level distribution of the participants in the present study.

\section{Measures}

The platform created for study 2 in the present study was further with the addition of a profile photo trustworthiness assessment module. To measure the perceived trustworthiness of the hosts, the respondents were asked directly to evaluate the trustworthiness of the hosts on a 10-point Likert scale after assessing the apartment evaluation screens.

\section{Analysis and results}

A paired samples t-test revealed significant differences between the perceived trustworthiness levels of the different profile photo types (Table $6)$. 
Table 6. Perceived trustworthiness of profile photos

\begin{tabular}{|c|c|c|c|c|c|}
\hline Pair & Profile Photo & Mean & Profile Photo & Mean & \\
\hline 1 & Neutral Expression & $\begin{array}{c}5.17 \\
(1.80)\end{array}$ & $\begin{array}{l}\text { Neutral expression } \\
\text { fWHR increased }\end{array}$ & $\begin{array}{c}4.79 \\
(1.81)\end{array}$ & $\mathrm{t}=4.392$ \\
\hline 2 & Neutral Expression & $\begin{array}{c}5.17 \\
(1.80)\end{array}$ & Happy Expression & $\begin{array}{c}6.21 \\
(1.95)\end{array}$ & $\mathrm{t}=10.862$ \\
\hline 3 & $\begin{array}{c}\text { Neutral expression } \\
\text { fWHR increased }\end{array}$ & $\begin{array}{c}4.79 \\
(1.81)\end{array}$ & Happy Expression & $\begin{array}{c}6.21 \\
(1.95)\end{array}$ & $t=13.029$ \\
\hline
\end{tabular}

These results suggest that profile photos have a significant effect on the perceived trustworthiness of the hosts. Hosts with happy expressions in their profile photos were perceived as the most trustworthy, while neutral expression fWHR-increased profile photos were perceived as the least trustworthy. Furthermore, in a paired samples t-test, significant differences were noted in the average preference scores of the happy expression, neutral expression and neutral expression fWHR-increased profile photos (Table 7).

Table 7. Paired samples t-test results of participants' apartment preferences

\begin{tabular}{|c|c|c|c|c|c|}
\hline Pair & Profile Photo & Mean & Profile Photo & Mean & \\
\hline 3 & Neutral Expression & $\begin{array}{c}5.92 \\
(2.69) \\
\end{array}$ & $\begin{array}{l}\text { Neutral expression } \\
\text { fWHR increased }\end{array}$ & $\begin{array}{c}5.72 \\
(2.71) \\
\end{array}$ & $\mathrm{t}=2.528$ \\
\hline 1 & Neutral Expression & $\begin{array}{c}5.92 \\
(2.69) \\
\end{array}$ & Happy Expression & $\begin{array}{c}6.31 \\
(2.65) \\
\end{array}$ & $\mathrm{t}=5.292$ \\
\hline 2 & $\begin{array}{l}\text { Neutral expression } \\
\text { fWHR increased }\end{array}$ & $\begin{array}{c}5.72 \\
(2.71)\end{array}$ & Happy Expression & $\begin{array}{c}6.31 \\
(2.65)\end{array}$ & $\mathrm{t}=6.088$ \\
\hline \multicolumn{6}{|c|}{ For all t-tests: $\mathrm{t}(225), \mathrm{p}<.02$} \\
\hline
\end{tabular}

These results reveal the effect of profile photos on user preferences. While the postings with happy expression profile photos had the highest rating on average, those with neutral expression fWHR-increased profile photos recorded the lowest average scores. A simple linear regression analysis was carried out to identify any correlation between perceived trustworthiness and user preferences, with the aim being to predict venue preferences based on the perceived trustworthiness of each host's profile photo type. Significant regression equations were found for happy expression profile photos $\left(\mathrm{R}^{2}=0.307, \mathrm{~F}(1,224)=99.325, \mathrm{p}<0.000\right)$ and for those with neutral expressions $\left(\mathrm{R}^{2}=0.320, \mathrm{~F}(1,224)=105.635, \mathrm{p}<0.000\right)$. Preferences for the apartments in postings with happy expression profile photos increased by 0.554 , and by 0.566 for neutral expression photos. Similar 
results were found also for neutral expression fWHR-increased photos $\left(\mathrm{R}^{2}=\right.$ $0.288, \mathrm{~F}(1,224)=90.393, \mathrm{p}<0.000)$, while and preference for the apartment increased by 0.536 . These results indicate a significant relationship between perceived trustworthiness and preference for the apartment, thus $H 2, H 3$, and $H 4$ are supported.

\section{CONCLUSIONS}

As the accommodation branch of the sharing economy grows, it comes to face new challenges. Accommodation sharing has functional benefits, in terms of access, convenience and cost, but also provides the user with the hedonic experience of plunging into the life aesthetics or the de facto meeting of new people from different parts of the world. Staying in a stranger's home can come with some risks, and so trust is at the very center of the business model of accommodation platforms. The strong need for trust among the users of such platforms leads users to make use of any information that is available to them, but as shown in the present study, this information is not necessarily relevant, and consumers do not use it consciously. Some variables, such as profile photos, can affect the perception of the user, without them even being aware of it, and so users may make their decisions unconsciously (Todorov, 2008; Todorov et al., 2009). Accordingly, sharing economy platforms need to understand what users infer from both the visual and the non-visual information posted on their sites, and should design their sites accordingly to reduce potential biases, for which it is necessary to understand the effect of changes in these variables. While managers must understand each factor of trust-building to ensure the safety of their platforms, users must give weight to the means of engagement when connecting with people who may sometimes be very far away. The findings of the present study indicate the importance of host profile photos on accommodation sharing platforms in increasing the likelihood of attracting customers, and the selection of such photos could be improved with a tool built into platforms to be applied at the accommodation profile-creation stage. The findings of the present study further reveal the points that such a tool should prioritize to in the creation of profile photos. As factors in the global economy, the users of digital accommodation platforms must effectively address the needs of a diversity of traveler types, and must develop the necessary knowledge, skills and attitudes to make this new communication platform instant and effective. Adding specific data about the relationship between trust and facially expressed emotions and traits in different cultures may prevent 
misunderstandings during digital communications with world travelers from different social backgrounds who are complete strangers.

Of course, a trustworthy face is just one factor in the establishment of trust. As in any sector, in the provision of accommodation, there will be new incumbents and consumers over time that will bring different opportunities and threats. One such threat could be the deceitful use of profile photos to take advantage of the factors identified in the present study. Accordingly, developing a good basis of knowledge of this communication modality will be beneficial to all stakeholders, and may contribute to their ability to foresee and circumvent such issues.

\section{Theoretical implications}

To the best of authors' knowledge, this is the first study in literature to combine a study of human facial variables, as a cognitive science with a study of the tourism and hospitality sector. Although there have been other studies identifying the variables affecting trustworthiness in profile photos (Barnes \& Kirshner, 2021; Ert et al., 2016; Jaeger et al., 2018), user behaviors and prices on accommodation-sharing platforms, the present study is the first to determine which variables related to the human face are effective in this regard. It is argued in the present study that during the formation of trust in a host and apartment choice behaviors on accommodationsharing platforms, the profile photos of the hosts grab the attention of users more than any other factors on profile pages. This is supported by claims in existing literature that (i) visual sensation is important for human conduct, (ii) one of the most important providers of visual sensation is the human face, (iii) the human face is a significant information source in the formation of trust among individuals, and (iv) the human face is interpreted by people from different backgrounds and cultures, universally, in the same way, instinctively and beyond individual control.

Inferences made about a person one has just met is a principal, automatic and immediate response of the human brain, while survivalrelated assessments are made even faster. Humans constantly collect information from their environment in order to survive, and develop the necessary attitudes to attain their goals. During such processes, they use cognitive filters to select the necessary information, and make inferences accordingly. After meeting a stranger, the perception of trustworthiness is established within $33 \mathrm{~ms}$, which is not something the human mind is able to perceive consciously (Todorov et al., 2009), and the unconscious side then completes the evaluation to guide behaviors (Kahneman, 2011). 
Thus, contact with others is the first step in the establishment of trust, during which, along with verbal conversations, nonverbal facial signals augment the transmission of meaning. Our dynamic facial expressions and static traits convey volumes of information that have an impact on our perceived trustworthiness.

The present study investigates how the visual-based trust process occurs in real life through the introduction of a simulated accommodation platform, while introducing an extended, multi-disciplinary approach to the field of accommodation-sharing by: (i) integrating data collected using an eye-tracking device, (ii) making use of a scientifically proven face database, and (iii) applying fWHR literature to the accommodationsharing field.

The findings that (i) happy facial expressions of hosts increase perceived trustworthiness, (ii) the perceived trustworthiness of hosts in their profile photos affects the apartment choices of users, with the apartments of hosts with higher perceived trustworthiness being preferred more by guests, and (iii) a negative correlation exists between increased fWHR and trustworthiness, all support and enrich the findings of existing studies by adding data from Turkey. The findings make further specific contributions to literature on accommodation-sharing platforms, revealing that (i) the profile photos of hosts are the most attention-grabbing variables for users of such platforms, and (ii) fWHR affects the apartment choices of users, with higher fWHRs decreasing the perceived trustworthiness of the hosts, resulting in their apartments being preferred less by guests. The results of the study concur with existing studies citing the importance of facial traits and expressions in the assessments of others. This data from Turkey, focusing solely on happiness as an emotion, contributes to these discussions, and may be expanded upon with researches in different countries.

\section{Limitations}

There are some limitations to the present study that should be noted. First, the introduced facial expressions were limited to males. Although Özener's (2012) study of the Turkish population found fWHR not to be dimorphic between genders, the authors of the present study limited their data to a single gender to eliminate the potential distortive impact of stereotypes on perceptions. 
Secondly, although the demographics of the participants in the present study fit the general profile of accommodation-sharing platform users, they were mainly university students and professors, and this may be considered a limitation of the study preventing the generalization of the findings to the general user population.

\section{Future research}

The results of the present study indicate the importance of profile photos when designing sharing economy platforms. The main variable used in the research is a still, static photo, being a two-dimensional source of stimulus with the ability to affect how emotions and traits are perceived. Further benefit in this regard could be garnered from studies investigating the impact of different dimensions, displays, framing, size and location of profile photos on screens. Considering the advances in 3D transmissions, assessing the impact of videos of faces, animated faces, as well as avatars, will provide further clues to the creators of future platforms in the sharing economy.

\section{ACKNOWLEDGEMENT}

This work was supported by the Research Fund of the Marmara University under Grant SOS-B-070317-0120.

\section{REFERENCES}

2020 Airbnb Update. (2020). Retrieved January 6, 2021, from https://news.airbnb.com/2020update/

Albinsson, P. A., \& Perera, B. Y. (2009). From trash to treasure and beyond: The meaning of voluntary disposition. Journal of Consumer Behaviour, 8(6), 340-353. https://doi.org/10.1002/cb.301

Bagozzi, R. P., \& Dholakia, U. M. (2006). Open source software user communities: A study of participation in Linux user groups. Management Science, 52(7), 1099-1115. https://doi.org/10.1287/mnsc.1060.0545

Bahrick, H. P., Bahrick, P. O., \& Wittlinger, R. P. (1975). Fifty years of memory for names and faces: A cross-sectional approach. Journal of Experimental Psychology: General, 104(1), 54-75. https://doi.org/10.1037/0096-3445.104.1.54

Bardhi, F., \& Eckhardt, G. M. (2012). Access-based consumption: The case of car sharing. Journal of Consumer Research, 39(4), 881-898. https://doi.org/10.1086/666376

Barnes, S. J., \& Kirshner, S. N. (2021). Understanding the impact of host facial characteristics on Airbnb pricing: Integrating facial image analytics into tourism research. Tourism Management, 83, 104235. https://doi.org/10.1016/j.tourman.2020.104235

Belleflamme, P., Lambert, T., \& Schwienbacher, A. (2014). Crowdfunding: Tapping the right crowd. Journal of Business Venturing, 29(5), 585-609. https://doi.org/10.1016/j.jbusvent.2013.07.003 
Bente, G., Baptist, O., \& Leuschner, H. (2012). To buy or not to buy: Influence of seller photos and reputation on buyer trust and purchase behavior. International Journal of Human-Computer Studies, 70(1), 1-13. https://doi.org/10.1016/j.ijhcs.2011.08.005

Beutin, N. (2017). Share economy 2017 the new business model. In PwC. Retrieved January 05, 2019, from https://www.pwc.at/de/publikationen/branchen-undwirtschaftsstudien/share-economy-report-

2017.pdf\%0Ahttps://www.pwc.de/de/digitale-transformation/share-economyreport-2017.pdf

Botsman, R., \& Rogers, R. (2010). What's Mine Is Yours: The Rise of Collaborative Consumption. New York: HarperCollins Publishers.

Carré, J. M., \& McCormick, C. M. (2008). In your face: Facial metrics predict aggressive behaviour in the laboratory and in varsity and professional hockey players. Proceedings of the Royal Society B: Biological Sciences, 275, 2651-2656. https://doi.org/10.1098/rspb.2008.0873

Carré, J. M., McCormick, C. M., \& Mondloch, C. J. (2009). Facial structure is a reliable cue of aggressive behavior. Psychological Science, 20(10), 1194-1198. https://doi.org/10.1111/j.1467-9280.2009.02423.x

Carré, J. M., Morrissey, M. D., Mondloch, C. J., \& McCormick, C. M. (2010). Estimating aggression from emotionally neutral faces: Which facial cues are diagnostic? Perception, 39(3), 356-377. https://doi.org/10.1068/p6543

Cassia, V. M., Turati, C., \& Simion, F. (2004). Can a nonspecific bias toward top-heavy patterns explain newborns' face preference? Psychological Science, 15(6), 379-383. https://doi.org/10.1111/j.0956-7976.2004.00688.x

Chang, L. J., Doll, B. B., van 't Wout, M., Frank, M. J., \& Sanfey, A. G. (2010). Seeing is believing: Trustworthiness as a dynamic belief. Cognitive Psychology, 61(2), 87-105. https://doi.org/10.1016/j.cogpsych.2010.03.001

Cheung, C.-K., \& Chan, C.-M. (2000). Social-cognitive factors of donating money to charity, with special attention to an international relief organization. Evaluation and Program Planning, 23(2), 241-253. https://doi.org/10.1016/S0149-7189(00)00003-3

Denegri-Knott, J., \& Molesworth, M. (2009). "I'll sell this and I'll buy them that": eBay and the management of possessions as stock. Journal of Consumer Behaviour, 8(6), 305315. https://doi.org/10.1002/cb.295

Devue, C., \& Grimshaw, G. M. (2017). Faces are special, but facial expressions aren't: Insights from an oculomotor capture paradigm. Attention, Perception, and Psychophysics, 79(5), 1438-1452. https://doi.org/10.3758/s13414-017-1313-x

Eckel, C. C., \& Petrie, R. (2011). Face value. American Economic Review, 101(4), 1497-1513. https://doi.org/10.1257/aer.101.4.1497

Ekman, P. (1993). Facial expression and emotion. American Psychologist, 48(4), 384-392. https://doi.org/10.1037/0003-066x.48.4.384

Ekman, P., Friesen, W. V., \& Hager, J. C. (2002). Facial action coding system: the manual. Salt Lake City: UT: Research Nexus.

Engell, A. D., Haxby, J. V., \& Todorov, A. (2007). Implicit trustworthiness decisions: Automatic coding of face properties in the human amygdala. Journal of Cognitive Neuroscience, 19(9), 1508-1519. https://doi.org/10.1162/jocn.2007.19.9.1508

Ert, E., Fleischer, A., \& Magen, N. (2016). Trust and reputation in the sharing economy: The role of personal photos in Airbnb. Tourism Management, 55, 62-73. https://doi.org/10.1016/j.tourman.2016.01.013

Ewing, L., Caulfield, F., Read, A., \& Rhodes, G. (2015). Perceived trustworthiness of faces drives trust behaviour in children. Developmental Science, 18(2), 327-334. 
https://doi.org/10.1111/desc.12218

Geniole, S. N., Molnar, D. S., Carré, J. M., \& McCormick, C. M. (2014). The facial width-toheight ratio shares stronger links with judgments of aggression than with judgments of trustworthiness. Journal of Experimental Psychology: Human Perception and Performance, 40(4), 1526-1541. https://doi.org/10.1037/a0036732

Grammer, K., \& Thornhill, R. (1994). Human (homo-sapiens) facial attractiveness and sexual selection - the role of symmetry and averageness. Journal of Comparative Psychology, 108(3), 233-242. https://doi.org/10.1037/0735-7036.108.3.233

Guttentag, D. (2015). Airbnb: disruptive innovation and the rise of an informal tourism accommodation sector. Current Issues in Tourism, 18(12), 1192-1217. https://doi.org/10.1080/13683500.2013.827159

Haselhuhn, M. P., Ormiston, M. E., \& Wong, E. M. (2015). Men's facial width-to-height ratio predicts aggression: A meta-analysis. PLoS ONE, 10(4), e0122637. https://doi.org/10.1371/journal.pone.0122637

Hassin, R., \& Trope, Y. (2000). Facing faces: Studies on the cognitive aspects of physiognomy. Journal of Personality and Social Psychology, 78(5), 837-852. https://doi.org/10.1037//0022-3514.78.5.837

Hehman, E., Leitner, J. B., Deegan, M. P., \& Gaertner, S. L. (2013). Facial structure is indicative of explicit support for prejudicial beliefs. Psychological Science, 24(3), 289-296. https://doi.org/10.1177/0956797612451467

Henderson, J. M., Nuthmann, A., \& Luke, S. G. (2013). Eye movement control during scene viewing: immediate effects of scene luminance on fixation durations. Journal of Experimental Psychology: Human Perception and Performance, 39(2), 318-322. https://doi.org/10.1037/a0031224

Hennig-Thurau, T., Henning, V., \& Sattler, H. (2007). Consumer file sharing of motion pictures. Journal of Marketing, 71(4), 1-18. https://doi.org/10.1509/jmkg.71.4.1

Hershler, O., \& Hochstein, S. (2005). At first sight: A high-level pop out effect for faces. Vision Research, 45(13), 1707-1724. https://doi.org/10.1016/j.visres.2004.12.021

Hofstede, G. (2018). What about Turkey? Retrieved January 6, 2019, from https://www.hofstede-insights.com/country/turkey/

iMotions. (2017). iMotions Biometric Research Platform 7.2, iMotions A/S, Copenhagen, Denmark.

Jaeger, B., Sleegers, W. W. A., Evans, A. M., Stel, M., \& van Beest, I. (2018). The effects of facial attractiveness and trustworthiness in online peer-to-peer markets. Journal of Economic Psychology, (May), 1-10. https://doi.org/10.1016/j.joep.2018.11.004

Jaeger, B., Sleegers, W. W. A., Evans, A. M., Stel, M., \& van Beest, I. (2019). The effects of facial attractiveness and trustworthiness in online peer-to-peer markets. Journal of Economic Psychology, 75(October 2018), 102125. https://doi.org/10.1016/j.joep.2018.11.004

Kahneman, D. (2011). Thinking, fast and slow. Farrar, Straus and Giroux.

Kim, M., Chung, N., \& Lee, C. (2011). The effect of perceived trust on electronic commerce: Shopping online for tourism products and services in South Korea. Tourism Management, 32(2), 256-265. https://doi.org/10.1016/j.tourman.2010.01.011

Konda. (2012). Gündelik hayatta güven. Retrieved January 6, 2019, from http://konda.com.tr/wp-

content/uploads/2017/03/KONDA_1209_GUNDELIK_HAYATTA_GUVEN.pdf

Kramer, R. S. S. (2016). Within-person variability in men's facial width-to-height ratio. PeerJ, 4, e1801. https://doi.org/10.7717/peerj.1801

Krumhuber, E., Manstead, A. S. R., Cosker, D., Marshall, D., Rosin, P. L., \& Kappas, A. 
(2007). Facial dynamics as indicators of trustworthiness and cooperative behavior. Emotion, 7(4), 730-735. https://doi.org/10.1037/1528-3542.7.4.730

Langner, O., Dotsch, R., Bijlstra, G., Wigboldus, D. H. J., Hawk, S. T., \& van Knippenberg, A. (2010). Presentation and validation of the Radboud Faces Database. Cognition $\mathcal{E}$ Emotion, 24(8), 1377-1388. https://doi.org/10.1080/02699930903485076

Langton, S. R. H., Law, A. S., Burton, A. M., \& Schweinberger, S. R. (2008). Attention $\begin{array}{llll}\text { capture by } \quad \text { faces. } & \text { 330-342. }\end{array}$ https://doi.org/10.1016/j.cognition.2007.07.012

Lauterbach, D., Truong, H., Shah, T., \& Adamic, L. (2009). Surfing a web of trust: Reputation and reciprocity on couchsurfing.com. 2009 International Conference on Computational Science and Engineering, 346-353. https://doi.org/10.1109/CSE.2009.345

Lefevre, C. E., \& Lewis, G. J. (2014). Perceiving aggression from facial structure: Further evidence for a positive association with facial width-to-height ratio and masculinity, but not for moderation by self-reported dominance. European Journal of Personality, 28(6), 530-537. https://doi.org/10.1002/per.1942

Lefevre, C. E., Lewis, G. J., Perrett, D. I., \& Penke, L. (2013). Telling facial metrics : Facial width is associated with testosterone levels in men. Evolution and Human Behavior, 34(4), 273-279. https://doi.org/10.1016/j.evolhumbehav.2013.03.005

Liu, C. S. (2012). A couchsurfing ethnography: Traveling and connection in a commodified world. Inquiries Journal, 4(7). Retrieved May 6, 2016, from http://www.inquiriesjournal.com/articles/669/2/a-couchsurfing-ethnographytraveling-and-connection-in-a-commodified-world

Mignault, A., \& Chaudhuri, A. (2003). The many faces of a neutral face: Head tilt and perception of dominance and emotion. Journal of Nonverbal Behavior, 27(2), 111-132. https://doi.org/10.1023/A:1023914509763

Mondloch, C. J., Lewis, T. L., Budreau, D. R., Maurer, D., Dannemiller, J. L., Stephens, B. R., \& Kleiner-Gathercoal, K. A. (1999). Face perception during early infancy. Psychological Science, 10(5), 419-422. https://doi.org/10.1111/1467-9280.00179

Montepare, J. M., \& Dobish, H. (2003). The contribution of emotion perceptions and their overgeneralizations to trait impressions. Journal of Nonverbal Behavior, 27(4), 237254. https://doi.org/10.1023/A:1027332800296

Neth, D., \& Martinez, A. M. (2009). Emotion perception in emotionless face images suggests a norm-based representation. Journal of Vision, 9(1), 1-11. https://doi.org/10.1167/9.1.5

Nowak, B., Allen, T., Rollo, J., Lewis, V., He, L., Chen, A., ... Young, E. (2015). Who will Airbnb hurt more - hotels or OTAs? Retrieved May 23, 2016, from http://linkback.morganstanley.com/web/sendlink/webapp/f/91f3j168-3pcc-g01hb8bf005056013100?store=0\&d=UwBSZXN1YXJjaF9NUwBiNjVjYzAyNi04NGQ2LTExZ TUtYjFIMi03YzhmYTAzZWU4ZjQ\%3D\&user=bdvpwh9kcvqs49\&_gda_=1573813969_cf5a3761794d8651f8618fc7a544cb82

Nuthmann, A., Smith, T. J., Engbert, R., \& Henderson, J. M. (2010). CRISP: A computational model of fixation durations in scene viewing. Psychological Review, 117(2), 382-405. https://doi.org/10.1037/a0018924

Ortiz-Ospina, E., \& Roser, M. (2018). Trust. Retrieved January 2, 2019, from https://ourworldindata.org/trust

Ozanne, L. K., \& Ballantine, P. W. (2010). Sharing as a form of anti-consumption? An examination of toy library users. Journal of Consumer Behaviour, 9(6), 485-498. 
https://doi.org/10.1002/cb.334

Özener, B. (2012). Facial width-to-height ratio in a Turkish population is not sexually dimorphic and is unrelated to aggressive behavior. Evolution and Human Behavior, 33(3), 169-173. https://doi.org/10.1016/j.evolhumbehav.2011.08.001

Ponte, E. B., Carvajal-Trujillo, E., \& Escobar-Rodríguez, T. (2015). Influence of trust and perceived value on the intention to purchase travel online: Integrating the effects of assurance on trust antecedents. Tourism Management, 47, 286-302. https://doi.org/10.1016/j.tourman.2014.10.009

Postigo, H. (2003). Emerging sources of labor on the internet: The case of America online volunteers. International Review of Social History, 48(11), 205-223. https://doi.org/10.1017/S0020859003001329

Reagle, J. M. J. (2010). Good Faith Collaboration: The Culture of Wikipedia. Cambridge, Massachusetts; London, England: The MIT Press. doi:10.2307/j.ctt5hhhnf

Resnick, P., \& Zeckhauser, R. (2002). Trust among strangers in internet transactions: Empirical analysis of eBay's reputation system. The Economics of the Internet and ECommerce, 127-157. https://doi.org/10.1016/S0278-0984(02)11030-3

Rezlescu, C., Duchaine, B., Olivola, C. Y., \& Chater, N. (2012). Unfakeable facial configurations affect strategic choices in trust games with or without information about past behavior. PLoS ONE, 7(3), e34293. https://doi.org/10.1371/journal.pone.0034293

Rhodes, G. (2006). The evolutionary psychology of facial beauty. Annual Review of Psychology, 57, 199-226. https://doi.org/10.1146/annurev.psych.57.102904.190208

Secord, P. F. (1958). Facial features and inference processes in interpersonal perception. In R. Taguiri \& L. Petrullo (Eds.), Person Perception and Interpersonal Behavior (pp. 300315). Stanford, CA: Stanford University Press.

Sinclair, G., \& Green, T. (2015). Download or stream? Steal or buy? Developing a typology of today's music consumer. Journal of Consumer Behaviour, 15(1), 3-14. https://doi.org/10.1002/cb.1526

Stirrat, M., \& Perrett, D. I. (2010). Valid facial cues to cooperation and trust: Male facial width and trustworthiness. Psychological Science, 21(3), 349-354. https://doi.org/10.1177/0956797610362647

Tingley, D. (2014). Face-off: Facial features and strategic choice. Political Psychology, 35(1), 35-55. https://doi.org/10.1111/pops.12041

Todorov, A. (2008). Evaluating faces on trustworthiness: An extension of systems for recognition of emotions signaling approach/avoidance behaviors. Annals of the New York Academy of Sciences, 1124, 208-224. https://doi.org/10.1196/annals.1440.012

Todorov, A., Pakrashi, M., \& Oosterhof, N. N. (2009). Evaluating faces on trustworthiness after minimal time exposure. Social Cognition, 27(6), 813-833. https://doi.org/10.1521/soco.2009.27.6.813

Todorov, A., Said, C. P., Engell, A. D., \& Oosterhof, N. N. (2008). Understanding evaluation of faces on social dimensions. Trends in Cognitive Sciences, 12(12), 455-460. https://doi.org/10.1016/j.tics.2008.10.001

Tussyadiah, I. P., \& Park, S. (2018). When guests trust hosts for their words: Host description and trust in sharing economy. Tourism Management, 67, 261-272. https://doi.org/10.1016/j.tourman.2018.02.002

Valentine, K. A., Li, N. P., Penke, L., \& Perrett, D. I. (2014). Judging a man by the width of his face: The role of facial ratios and dominance in mate choice at speed-dating events. 
https://doi.org/10.1177/0956797613511823

Valenza, E., Simion, F., Cassia, V. M., \& Umiltà, C. (1996). Face preference at birth. Journal of Experimental Psychology: Human Perception and Performance, 22(4), 892-903. https://doi.org/10.1037/0096-1523.22.4.892

Van't Wout, M., \& Sanfey, A. G. (2008). Friend or foe: The effect of implicit trustworthiness judgments in social decision-making. Cognition, 108(3), 796-803. https://doi.org/10.1016/j.cognition.2008.07.002

Voss, J. (2005). Measuring wikipedia. Growth Lakeland, 1-12. https://doi.org/10.1145/1641309.1641364

Weston, E. M., Friday, A. E., \& Liò, P. (2007). Biometric evidence that sexual selection has shaped the hominin face. PLoS ONE, 2(8), e710. https://doi.org/10.1371/journal.pone.0000710

Willis, J., \& Todorov, A. (2006). First impressions: Making up your mind after a 100-ms exposure to a face. Psychological Science, 17(7), 592-598. https://doi.org/10.1111/j.1467-9280.2006.01750.x

Wilson, R. K., \& Eckel, C. C. (2006). Judging a book by its cover: Beauty and expectations in the trust game. Political Research Quarterly, 59(2), 189-202. https://doi.org/10.1177/106591290605900202

Wu, J., Ma, P., \& Xie, K. L. (2017). In sharing economy we trust: The effects of host attributes on short-term rental purchases Jiang. International Journal of Contemporary Hospitality Management, 29(11), 2962-2976. https://doi.org/10.1108/IJCHM-08-20160480

Xie, K. L., \& Mao, Z. (2017). The impacts of quality and quantity attributes of Airbnb hosts on listing performance. International Journal of Contemporary Hospitality Management, 29(9), 2240-2260. https://doi.org/10.1108/IJCHM-07-2016-0345

Zebrowitz, L. A., Voinescu, L., \& Collins, M. A. (1996). “Wide-eyed" and "crooked-faced": Determinants of perceived and real honesty across the life span. Personality and Social Psychology Bulletin, 22(12), 1258-1269. https://doi.org/10.1177/01461672962212006

Zervas, G., Proserpio, D., \& Byers, J. W. (2017). The rise of the sharing economy: Estimating the impact of Airbnb on the hotel industry. Journal of Marketing Research, 54(5), 687705. https://doi.org/10.1509/jmr.15.0204

Zhang, L., Yan, Q., \& Zhang, L. (2018). A computational framework for understanding antecedents of guests' perceived trust towards hosts on Airbnb. Decision Support Systems, 115(November), 105-116. https://doi.org/10.1016/j.dss.2018.10.002 